\title{
DESIGN OF MANIPULATOR ROBOT IN UNMANNED GRENADE TAMER (UGT)
}

\author{
Ayip Rivai Prabowo, Endro Prasetijoadi, Dueng Deriva, Wawan Kusdiana \\ Indonesian Naval Technology College, STTAL Surabaya Indonesia
}

\begin{abstract}
Low safety factor in the Standard Operating Procedure (SOP) in handling grenades that fail to explode at the training location can be fatal for personnel and instructors. In a previous study, a stick manipulator was designed. However, this tool has disadvantages because the operator is too close to explosives. By considering the security of personnel, the authors make "Design Robot Manipulator Build on Unmanned Grenade Tamer (UGT)". This tool is used to assist trainers and instructors in the implementation of laying explosives as a procedure for handling grenades that do not explode properly in position. The mechanism of this tool is made to complement the base tank that is driven by a robot remote control system that moves using a servo motor as an actuator. The total length of the horizontal arm stretch is $780 \mathrm{~mm}$ and 795 $\mathrm{mm}$ for the vertical stretch. Arm foundation is designed capable of rotating as far as $120^{\circ}$. Link 1 moves $150^{\circ}$, link $2150^{\circ}$, Link 31801 , and wrist roll $90^{\circ}$. The force acting on link 1 is $16.758 \mathrm{~N}$ in the direction of the $y$-axis parallel force, torque is $5.5 \mathrm{Nm}$ and with an angular acceleration of $142 \mathrm{rad} / \mathrm{s}^{2}$. On the link 2 force of $16.66 \mathrm{~N}$, the direction of the force is parallel to the $y$ axis, torque of $9.4 \mathrm{Nm}$ and angular acceleration of 496rad / $\mathrm{s}^{2}$. And on the 3 link force of $14.7 \mathrm{~N}$ of torque of $3.3 \mathrm{Nm}$ and angular acceleration of 293rad / $\mathrm{s}^{2}$. The gripper gripping force is $1,158 \mathrm{kgf}$ which is driven by a servo motor with a minimum torque of $5.42 \mathrm{Nm}$.
\end{abstract}

Keywords: Robot arm, Torque, Gripper

\section{INTRODUCTION \\ 1.1 Background}

From the data taken in the field, several accidents were recorded at the training ground when personnel operated weapons or were securing explosives. The author took one case in 2014 that happened to Serka Siswadi, a grenade throwing instructor who had an accident while securing a grenade that failed to explode at the training location. As a result of the incident, he lost both hands and had to be helped by using a robotic arm.

Responding to the problems that occur above, it is necessary to carry out research or development of equipment that can support the duties of soldiers in the training field. Where is a tool that can be operated with the priority of personnel safety.

At present, many can be found in the field both in the industrial world and in military equipment that is moved robotically. This is done because it fulfills various kinds of demands, including the demands of mass production and minimizing the occurrence of human errors. The robot that is often encountered is an arm robot. Robot arms are very popular in the world of robotics for the future. Arm robot or it can be called a robot manipulator is a mechanical system that works like a human arm consisting of an arm (link) and a joint which shows the movement of the robot.

\subsection{Problem Formulation}

Based on the background above, it will be formulated how to design a manipulator robot on an Unmanned Grenade Tamer (UGT) that is proportional to the base tank according to the expected functions and specifications. Therefore the things that need to be discussed in this research are as follows:

a. Designing the 5 Degre Off Freedom (DOF) robot arm model.

b. Planning servo motors on joints 1,2 and 3.

c. Planning the wrist roll pivot and joint brace 2 .

d. Planning the servo motor drive motor.

\subsection{Research purposes}

a. Creating a robot manipulator design to complement the ideal 
Unmanned Grenade Tamer (UGT) construction with a base tank construction and can be applied well in the field.

b. Get the ideal calculation for planning a servo motor capable of moving the manipulator robot properly and safely.

c. Obtain a secure size on the wrist roll pivot and joint brace 2 .

d. Obtain a torque calculation for the appropriate gripper drive servo motor.

\section{BASIC THEORY}

\subsection{Configuration of robot}

Robot configuration is a link and joint stacking pattern that produces certain movement characteristics.

This is commonly called the degrees of freedom. The degrees of freedom (DOF) of a robotic system can be compared as the human body moves

The three degrees of freedom of movement on the arm are:

1. Rotational travers.

2. Radial travers.

3. Vertical travers.

\subsection{Arm joints}

Single Link Arm robots are the first step in studying more complex robotic structures such as multiple arm manipulator robots or humanoid robots. It is said that the arm robot is one joint because this robot has 1 joint and 1 arm or also known as 1 Degree Of Freedom (DOF). If the robot is given a command to move the arm, the robot arm will move at the $x$ and $y$ coordinates. The $x, y$ and $z$ coordinates represent the direction of transformation of each component of the joint space. The $z$ coordinate cannot be displayed on a 2dimensional image because it is perpendicular to the direction of our view. In the Figure below the position of the tip of the arm is symbolized by $P$ at the point ( $x$ and $y$ ) while the radius ( $r$ ) is written as the length of the arm or link (I) and $\theta$ is the angle of the joint.

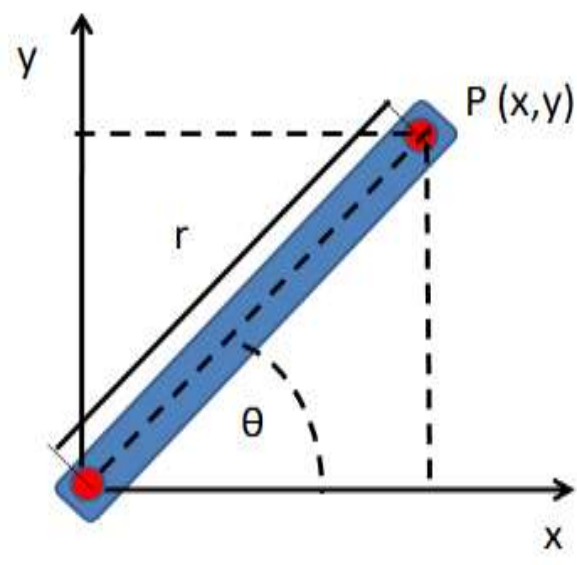

1 joint arm configuration

Possible directions of movement of a single joint robotic arm:

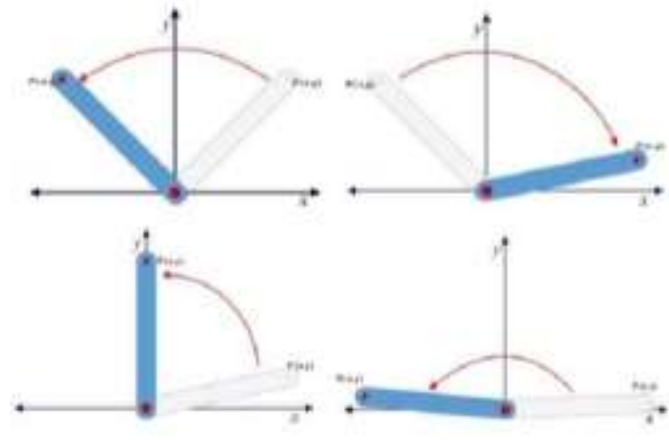

Variation in the direction of motion of the arm

If the robot uses 3 joints, it says the robot has 3 DOF. The robot consists of 3 joints and 3 connected links, link 1 is the shoulder, link 2 is the elbow, and link 3 is the wrist.

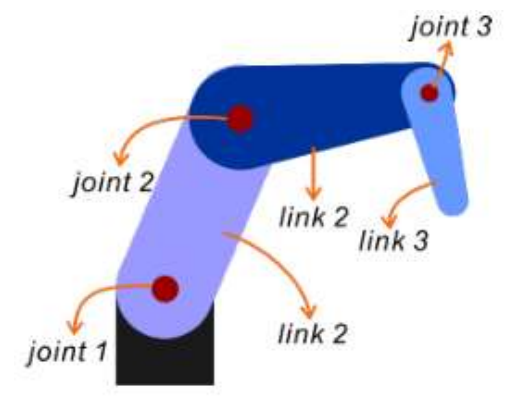

3 DOF robot design

The direction of movement of the robot moves at the $x$ and $y$ coordinates. As exemplified in the following picture: 


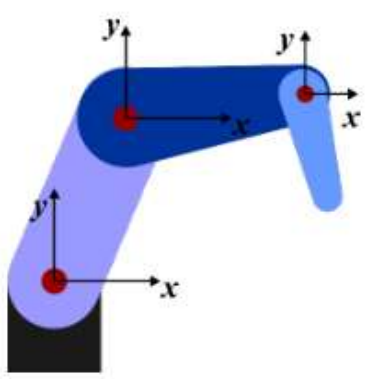

3 DOF robot movement direction

The 3 DOF articulated robot work area is reached according to the direction of its movement. This robot has 3 rotational movements at the $\mathrm{x}$ and $\mathrm{y}$ coordinates, which allows each joint of the robot to move up and down as far as $\pm 180^{\circ}$. The working area of arm 1 is determined by the length of $\mathrm{r} 1$, the working area of arm 2 is determined by the length of $r 2$ plus the area of work 1 , and the working area 3 is determined by the length of the arm $r 3$ plus the area of work area 1 and 2 .

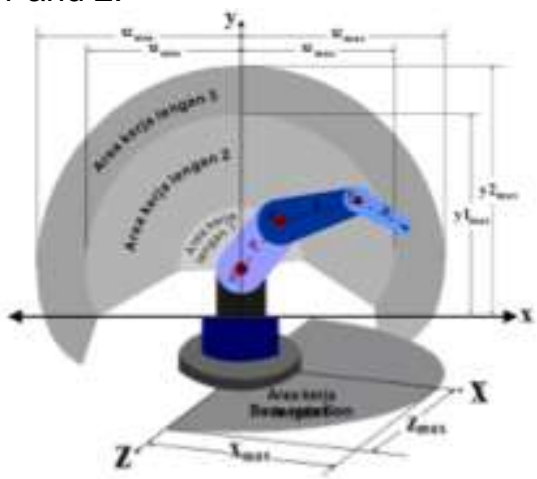

Articulated 3 DOF configuration work area and base rotation

One way to obtain a kinematic equation is to use a variable position of the arm or $\mathrm{P}(\mathrm{x}, \mathrm{y})$ which utilizes a trigonometric formula.

$$
\begin{aligned}
& x=r \cos \theta \\
& y=r \sin \theta
\end{aligned}
$$

If the point $(x, y)$ is known, it can be calculated by:

$$
\theta=\tan ^{-1}\left(\frac{y}{x}\right)
$$

To calculate the distance between the main axis of link 1 and the end of link 2 using the equation:

$$
R=\sqrt{\left(r_{1}{ }^{2}+r_{2}{ }^{2}+2 \cdot r_{1} \cdot r_{2} \cdot \cos \theta\right)}
$$

To calculate the angle between $R$ and the $\mathrm{x}$-axis expressed by:

R. $\sin \beta=r \cdot \sin \theta$
To determine the link direction 2 is denoted by :

$$
\tan \alpha=\frac{\left(x_{2}-x_{1}\right)}{\left(y_{1}-y_{2}\right)}
$$

To determine the angle $\alpha$ can be expressed by:

$$
\cos \alpha=\frac{A C^{2}+C B^{2}-A B^{2}}{2 \cdot A C \cdot C B}
$$

To determine the $x$-axis coordinates at the end of the link 3 using the phitagorean theory:

$$
x_{3}=x_{2}+\sqrt{\left(r_{3}{ }^{2}-y_{2}{ }^{2}\right)}
$$

To find the weight of the object expressed by:

$$
W=m \cdot g
$$

\subsection{Machine Element}

Machine elements are parts of a single component used in machine construction, and each part has a unique usage function. With the above understanding, the machine elements can be grouped as follows:

a. Connection elements.

b. Bearings and transmission elements.

c. Transmission elements for gas and liquid.

Basically, in planning machine elements it is part (component) planning, which is planned and made to meet the mechanical needs of a machine. In these planning stages, things that need to be considered in starting machine element planning include:

Types of loading planned.
a. Selection of materials.
b. The types of stresses caused by the loading.
c. Planned shape and size of machine parts.
The movement or kinematics of the parts to be planned.
a. Use of Standard components
b. Reflects a sense of beauty (estética aspect)
c. Operation safety
d. Legal and economicalPemeliharaan dan perawatan 
Taking into account the above considerations, the total planning stages are as follows:
a. Determine needs
b. Selection of mechanisms
c. Mechanism load
d. Material selection
e. Determine the size
f. Modification
g. Shop drawing
h. Manufacture and quality control

\subsection{Plotting the shaft}

Discussing the calculation of the shaft is discussing the material and its diameter. The stress borne by the shaft can be in the form of bending stress, torsional stress, combination stress, and so on. In general, shafts transmit power through belts, gears, chains and other transmissions. Therefore, the shaft receives both torsional and bending loads. To calculate the bending moment that occurs on the shaft, the following equation is used:

$$
M b=F . L
$$

Where :

$$
\begin{aligned}
& F=\text { force }(\mathrm{kgf}) \\
& L=\text { shaft length }(\mathrm{mm})
\end{aligned}
$$

Meanwhile, to calculate the moment of torque, the following equation is used:

$$
M t=716200 . \frac{N}{n}
$$

Where:

$$
\begin{aligned}
& \mathrm{Mt}=\text { torque moment (kgf.mm) } \\
& \mathrm{N}=\operatorname{power}(\mathrm{Hp}) \\
& \mathrm{n}=\text { turn (Rpm) }
\end{aligned}
$$

Due to the load from the combination of bending stress and torsional stress at the same time, the maximum stress that occurs can be stated:

$$
\tau \max =\sqrt{\left(\frac{\sigma_{\mathrm{x}}}{2}\right)^{2}+\tau^{2}}
$$

For solid axles :

$$
\sigma_{\mathrm{x}}=\frac{32 \cdot M b}{\pi \cdot d s^{3}} \operatorname{dan} \tau=\frac{16 \cdot M t}{\pi \cdot d s^{3}}
$$

According to (Sularso, 1997) the stress that occurs and the material safety requirements can be stated:

For solid axles :

$\tau \max =\frac{5,1}{d^{3}} \sqrt{M b^{2}+M t^{2}} \leq 0,58$. syp $/$ sf

Where :

$\mathrm{Mb}=$ bending moment (kgf.mm)

$\mathrm{Mt}=$ torque moment (kgf.mm)

\subsection{Pen}

To anticipate the yield strength of the material, the authors use several equations. The equation will be applied at several points that are considered to have the greatest burden. In planning the arm mechanism, the authors concluded that joint 2 received a greater load than the other.

For this reason, it is necessary to plan the diameter of the pen that is safe to use to hold the arm joint, the equation used is :

$$
\frac{F}{A}=|\tau|
$$

Where :

$$
\begin{aligned}
& F=\text { force }(N) \\
& A=\text { cross-sectional area }\left(\mathrm{mm}^{2}\right) \\
& |T|=\text { allowable stress }\left(\mathrm{kgf} / \mathrm{mm}^{2}\right)
\end{aligned}
$$

\section{$2.4 \quad$ Gripper}

Gripper models are generally tailored to the needs or objects to be grasped. The function of the gripper can be seen from the shape of the jaw. If the jaw is straight, it is generally used to grab objects with a flat surface. To take an object with a cylindrical shape, a gripper with a semicircular or angled jaw is required. To calculate the torque needed to grip the gripper, according to (R.S.Khurmi, J.K Ghupta, 1982) the equation used is:

$$
\text { Fa. } L=W t . x
$$


Where :

Fa: the force acting on the end of the gripper (N)

$\mathrm{L}$ : gripper arm length $(\mathrm{mm})$

$\mathrm{x}$ : transmission gear radius $(\mathrm{mm})$

Wt: tangential force $(\mathrm{N})$

\section{$2.5 \quad$ Style}

The SI units used to measure force are expressed in Newtons (N). The force itself is denoted by the symbol $F$, while for friction, it is denoted by fs or fk depending on the conditions. Newton's second law states that the resultant force acting on an object is equal to the rate at which its momentum changes over time. If the mass of the object is constant, then this law states that the object's acceleration is directly proportional to the force acting on the object and its direction is also in the direction of that force, expressed by :

$$
\boldsymbol{F}=\sum \boldsymbol{m} \cdot \boldsymbol{a}
$$

Where :

$$
\begin{aligned}
& \text { F: Style }(\mathrm{N}) \\
& \text { m: Mass }(\mathrm{Kg}) \\
& \text { a: Acceleration of gravity }\left(\mathrm{m} / \mathrm{s}^{2}\right)
\end{aligned}
$$

\subsection{Torque}

Torque or moment of force is a quantity that states the amount of force acting on an object causing the object to rotate. (Ardiyanto, 2019) The concept of torsion in physics, commonly called moments, begins with Archimedes' work on the liver. Torque can be thought of as the rotational force.

The rotational analogues of force, mass, and acceleration are torque, moment of inertia, and angular acceleration. The force acting on the lever, multiplied by the distance from the center of the lever, is the torque.

$$
\begin{aligned}
& \boldsymbol{T}=\boldsymbol{F} \cdot \boldsymbol{r} \\
& \text { Or } \quad T=F \cdot r(\text { if the direction }
\end{aligned}
$$

of the force is not perpendicular)

Where :

$\mathrm{T}$ : Torque $(\mathrm{Nm})$

r: Radius / Sleeve Length (m)

F: Style (N)

$\theta$ : Angle between the arm of force $r$ and force

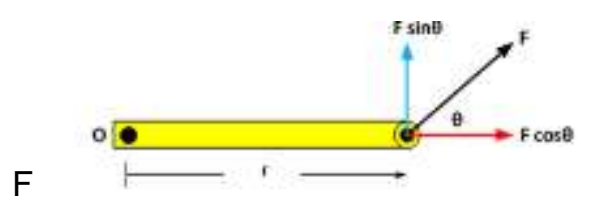
torque

The concept of a moment of force or

\section{RESEARCH METHODS}

\subsection{Research design}

This research is an experiment and development of previous research, and is an innovation to create a supporting tool in accordance with the background and problem formulations above. In this research, scientific calculations and adjustments will be carried out to determine the appropriate components in order to produce a tool as needed.

This research method is carried out by combining the structural design of a mechanical robot arm frame to move the Cartesian coordinate type material and calculating the drive system, frame construction. This research will use a quantitative approach. That is, where in a quantitative approach, many researchers are required to use numbers, starting from data collection, data processing and turning it into a tool..

\subsection{Research procedure}

In this research procedure, it will be discussed about the time and place of research as well as the tools and materials that will be used in making this tool, then the design, data collection and data processing. 


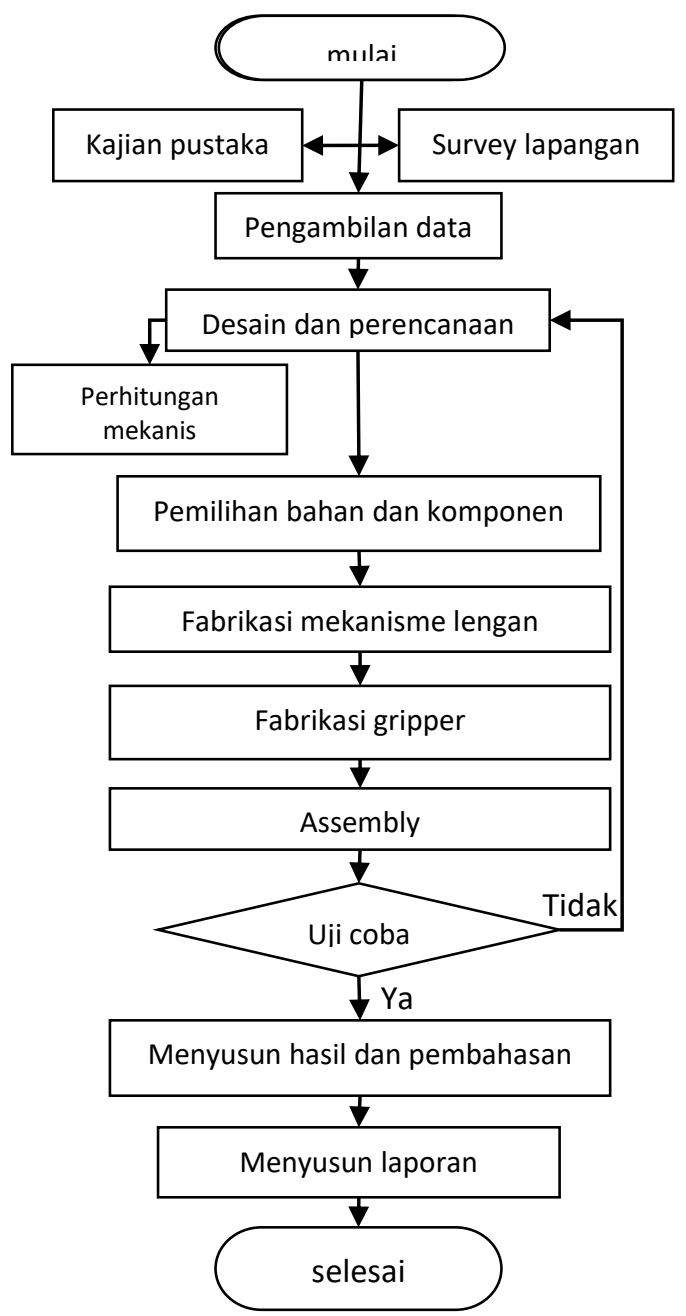

\section{DESIGN, IMPLEMENTATION AND TESTING \\ 4.1 Mechanical design}

The design that is meant by the author in this chapter is to design a robotic arm mechanism according to the expected function by considering the weight calculations taken, the maximum load of the arm and the configuration of the arm motion.

From the results of the calculations that will be carried out according to the design above, data will be obtained that can be used as a reference for determining the specifications of the servo motor. So that we get the servo motor specifications in accordance with the expected work objectives of the robot arm mechanism.

\section{a. Robot arm model design}

The robot arm has a basic link length specification of $15 \mathrm{~mm}$, link 1 (L1) $250 \mathrm{~mm}$, link 2 (L2) $380 \mathrm{~mm}$, and a distance of the end effector tip from joint 4 position as far as $150 \mathrm{~mm}$ (L3), so that the total length of the horizontal arm stretch is $780 \mathrm{~mm}$ and $795 \mathrm{~mm}$ for vertical stretches (Muhammad Fathul Faris, Aris Triwiyatno, Iwan Setiawan, 2012).

For each joint on the robot arm it is designed with each angle's reach. For joint $1(\theta 1)$ is $120^{\circ}$, joint $2(\theta 2)$ is $150^{\circ}$, joint $3(\theta 3)$ is $90^{\circ}$, joint $4(\theta 4)$ is $120^{\circ}$, and joint $5(\theta g)$ is $180^{\circ}$. For joint 5 as an end effector, the change in angle will be converted into a change in position (translation) of the gripper finger / jaw.

\section{b. Desain of Fondation Robot Arm}

The material used to make the foundation for the robot arm is aluminum. It takes 2 pieces of aluminum with a length of $180 \mathrm{~mm}$, a width of $140 \mathrm{~mm}$ and a thickness of 2 $\mathrm{mm}$. To support the foundation of the robot arm in order to obtain a rotating motion, axial trush ball bearings are selected with an inner diameter of 60 $\mathrm{mm}$, an outer diameter of $80 \mathrm{~mm}$ and a thickness of $15 \mathrm{~mm}$. Also needed is an aluminum plate with a thickness of 2 $\mathrm{mm}$ which is cut in a circle with a diameter of $58 \mathrm{~mm}$ as a coupling between the servo motor and the base of the foundation..

The steps in making the robot arm foundation are as follows:

1) The aluminum plate is cut to a predetermined size. 2 sheets long 180 $\mathrm{mm}, 140 \mathrm{~mm}$ wide and $2 \mathrm{~mm}$ thick. Make a hole in the center of the plate for the servo motor holder. Also make a rectangular hole for the base of the arm. Drill 6 holes on the edges of the two plates to lock the servo motor. 
Attach an L-shaped aluminum plate to support the base of the arm.

2) Cut a circular aluminum plate for the coupling between the servo motor and the base of the foundation with a diameter of $58 \mathrm{~mm}$. Drill in the center of the circle as a bolt hole for the servo motor holder. Then make 4 bolt holes to hold the coupling to the base of the foundation.

3) Assembling aluminum plate, servo motor, coupling and axial trush ball bearing at the base of the robot arm foundation.

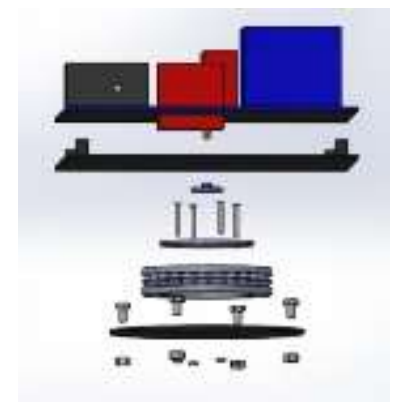

Robot arm oundation

\section{c. Robot arm frame}

To make the robot arm frame, aluminum is used as a base material with various thicknesses. The length of the material is cut according to the distance of the arm to adjust the height of the base tank. So that the movement of the arm from the base of the arm to the end of the gripper is able to reach the object to be taken. It is also necessary to pay attention to the balance of the arms when moving back and forth or when turning to the right and left. To make an arm frame, several materials are needed, including:

1) $13 / 4$ inch aluminum pipe with a length of $290 \mathrm{~mm}$, and a thickness of $1 \mathrm{~mm}$ (for the front arm).

2) 1 sheet of aluminum plate with a length of $350 \mathrm{~mm}$, a width of 150 $\mathrm{mm}$ and a thickness of $2 \mathrm{~mm}$ (for the servo housing).
3.1 aluminum holo with $270 \mathrm{~mm}$ long and $0.8 \mathrm{~mm}$ thick (for the back arm).

4) 4 aluminum moving levers to connect the servo motor with link 2 and link 3. Equipped with bearings with an inner diameter of $1.5 \mathrm{~mm}$, an outer diameter of $17 \mathrm{~mm}$ and a thickness of $1.5 \mathrm{~mm}$ at each joint.

5) 1 piece of AS aluminum as a connection for rotation on the joint 3. With a diameter of $60 \mathrm{~mm}$ and a length of $430 \mathrm{~mm}$

After all the materials are ready, there are several steps in the process of making the 6 axis robot arm. Among them are as follows:

1) Cut an aluminum plate with a length of $350 \mathrm{~mm}$, a width of 150 $\mathrm{mm}$ according to the expected model. Make a hole for the servo motor mount. Bend the aluminum plate. Drill on the right and left as joint holes.

2) The aluminum holo is cut 270 $\mathrm{mm}$ long. Drill at a distance of 10 $\mathrm{mm}$ from each end as joint holes.

3) Cut 290 inch aluminum pipe along $290 \mathrm{~mm}$. Also cut the aluminum plate to hold the front and rear pipes, and make a hole in the middle of the plate as the AS holes for joint rotation 3 
4) Cut AS for rotation of joint 3 along $430 \mathrm{~mm}$. Circular cut of $40 \mathrm{~mm}$ diameter aluminum plate for coupling AS joint 3 with servo motor.

\subsection{Calculating arm load}

In calculating the load, there are several variables that must be known. The first is the object's mass to be lifted. While the second calculation is the maximum load that occurs in the robot arm itself. For the first variable, it is quoted from (Suratno, Anton Suseno, Slamet Sigit Widodo, 2016) that there are two main tools or components of the load, namely TNT and tripot / buffer explosives.

It says that the total body mass of TNT and the supports is $1.23 \mathrm{~kg}$. Meanwhile, the second variable needs a more in-depth calculation. Each link has its own calculation. After knowing the calculation of each link, we can conclude the total load on the arm.

\section{a. Determine the coordinates $(x, y)$ of each joint}

Before finding the magnitude of the force that occurs in the robot arm, it is necessary to determine the amount of the angle so that the resultant vector can be found so that the coordinate points $P(x, y)$ of each joint can be found. If the angle $(\theta)$ is assumed to be in the direction $30^{\circ}$. Meanwhile, to determine the coordinate points $(x, y)$ as in the image below, several settlement methods are used as follows:

\section{1) Determinant Coordinat link 1.}

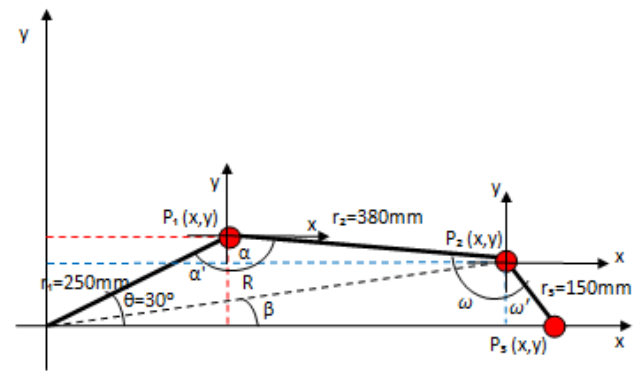

$\mathrm{y}_{1}=\mathrm{r}_{1} \cdot \sin \theta$

$=250 \mathrm{~mm} \cdot \sin 30$
$=125 \mathrm{~mm}$

$\mathrm{x}_{1}=\mathrm{r}_{1} \cdot \cos \theta$

$=250 \mathrm{~mm} \cdot \cos \pi 30$

$=216,5 \mathrm{~mm}$

So the coordinates $P_{1}(x, y)$ of the end of link 1 in the direction of $30^{\circ}$ are $\mathrm{x}_{1}=216 \mathrm{~mm}$ and $\mathrm{y}_{1}=125 \mathrm{~mm}$. If the direction of the link force 1 is parallel to the $y$ axis, then the direction of the force against link 1 can be stated:

$$
\begin{aligned}
\vec{F}= & 180^{\circ}-\left(90^{\circ}-\theta\right) \\
& =180^{\circ}-\left(90^{\circ}-30^{\circ}\right) \\
& =180^{\circ}-60^{\circ} \\
& =120^{\circ}
\end{aligned}
$$

the direction of force with respect to link 1 is $120^{\circ}$

\section{2) Determinant Coordinat link 2.}

Meanwhile, to find the coordinates $P_{2}(x, y)$ on link 2 the following methods are used:

To find the length of $R$ is:

$$
\begin{aligned}
& R=\sqrt{\left(r_{1}^{2}+r_{2}^{2}+2 \cdot r_{1}, r_{2}, \cos \theta\right)} \\
& =\sqrt{\left(250 \mathrm{~mm}^{2}+380 \mathrm{~mm}^{2}+2.250 \mathrm{~mm} \cdot 380 \mathrm{~mm} \cos 30\right)} \\
& =\sqrt{(62500 \mathrm{~mm}+144400 \mathrm{~mm}+164545 \mathrm{~mm})} \\
& =\sqrt{371445 \mathrm{~mm}} \\
& =609 \mathrm{~mm}
\end{aligned}
$$

Untuk mencari sudut $\beta$ adalah :

$$
R \cdot \sin \beta=r \cdot \sin \theta
$$

$609 \mathrm{~mm} \cdot \sin \beta=250 \mathrm{~mm} \cdot \sin 30$

$$
\sin \beta=\frac{(250 \mathrm{~mm} \cdot \sin 30)}{609 \mathrm{~mm}}
$$




$$
\begin{aligned}
& \sin \beta=0,205 \\
& \beta=11^{0}
\end{aligned}
$$

From the above calculations, you can find the $\mathrm{P}_{2}(\mathrm{x}, \mathrm{y})$ coordinates at the end of link 2 in the following way:

$$
\begin{aligned}
& y=R \cdot \sin \beta \\
= & 609 \mathrm{~mm} \cdot \sin 11,6 \\
= & 122 \mathrm{~mm} \\
& x=R \cdot \cos \beta \\
= & 609 \mathrm{~mm} \cdot \cos 11,6 \\
= & 597 \mathrm{~mm}
\end{aligned}
$$

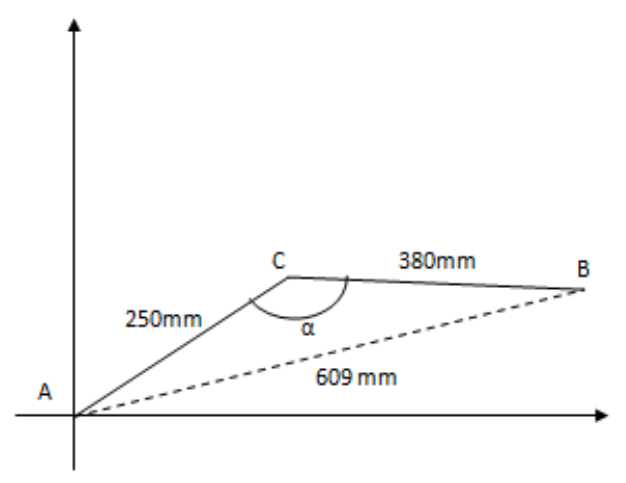

Angle a link 2

If the position of link 1 and link 2 is as in Figure 4.4, then to find the angle $\alpha$ can be determined in the following way:

$$
\begin{aligned}
& \cos \alpha=\frac{A C^{2}+C B^{2}-A B^{2}}{2 \cdot A C \cdot C B} \\
& =\frac{250^{2}+380^{2}-609^{2}}{2.250 .380} \\
& =\frac{62500+144400-370881}{190000} \\
& =\frac{-163981}{190000} \\
& =-0,863
\end{aligned}
$$

$$
\alpha=150^{\circ}
$$

To find the angle at point $B$ is:

$$
\begin{aligned}
& \cos B=\frac{A B^{2}+C B^{2}-A C^{2}}{2 \cdot A B \cdot C B} \\
& =\frac{609^{2}+380^{2}-250^{2}}{2.609 .380} \\
& =\frac{370881+144400-62500}{462840} \\
& =\frac{453}{462840} \\
& =0,98 \\
& <B=12^{\circ}
\end{aligned}
$$

If the direction of the link force 2 is parallel to the $y$ axis, then:

$$
\begin{aligned}
\vec{F} & =180^{\circ}-\left(\left(90^{\circ}-\beta\right)+<B\right) \\
& =180^{\circ}-\left(\left(90^{\circ}-11^{\circ}\right)+12^{0}\right) \\
& =180^{\circ}-91^{\circ} \\
& =89^{\circ}
\end{aligned}
$$

So the coordinate of the end of link 2 is $P_{2}(597 \mathrm{~mm}, 122 \mathrm{~mm})$, the direction of force against link 2 is $89^{\circ}$.

\section{Specifies the coordinates of the end of the link.}

Since the coordinates of the point $P_{3}(x, y)=(x, 0)$, to determine the coordinates of the point $x_{3}$ uses the Pythagorean theory by adding the distance of the point $x_{2}$ as follows:

$$
\begin{aligned}
x_{3}= & x_{2}+\sqrt{\left(r_{3}^{2}-y_{2}^{2}\right)} \\
& =597 m m+\sqrt{\left(150 m^{2}-122 m^{2}\right)} \\
& =597 m m+\sqrt{(22500 m m-14884 m m)} \\
& =597 m m+\sqrt{7616 m m} \\
=597 m m & =87 m m
\end{aligned}
$$


$=684 \mathrm{~mm}$

While the direction of link 3 about the axis $\mathrm{P}_{2}(\mathrm{x}, \mathrm{y})$ is:

$$
\begin{aligned}
& \tan \omega=\frac{x_{3}-x_{2}}{y_{2}-y_{3}} \\
& =\frac{684 \mathrm{~mm}-597 \mathrm{~mm}}{122 \mathrm{~mm}-0} \\
& =\frac{87 \mathrm{~mm}}{122 \mathrm{~mm}} \\
& =0,71 \\
& \omega=35^{\circ}
\end{aligned}
$$

If the direction of force on the tip of the link 3 is parallel to the $y$ axis, then:

$$
\begin{aligned}
& \vec{F}=180^{\circ}-\left(90^{\circ}-35^{\circ}\right) \\
& =180^{\circ}-55^{\circ} \\
& =125^{\circ}
\end{aligned}
$$

So the coordinates $\mathrm{P}_{3}(\mathrm{x}, \mathrm{y})$ at the end of link 3 are $x=684 \mathrm{~mm}$ and $y=0$, the direction of faya forms an angle of $125^{\circ}$ to link 3.

\section{a. Calculate the force on joints 1,2} and 3 .

Before calculating the amount of torque required by each joint, it is necessary to know how much force is applied to each joint. In order to obtain more accurate data, the calculation of the force starts from the force that occurs at the joint farthest from the base of the arm. The following will calculate the force that occurs in each joint:

Calculating the force on the link 3.

To calculate the force on joint 3 with the object load is :

$$
\boldsymbol{F}=\sum \boldsymbol{m} \cdot \boldsymbol{a}
$$

$$
\begin{aligned}
& F_{3}=1,5 \mathrm{~kg} \cdot 9,8 \mathrm{~m} / \mathrm{s}^{2} \\
& =14,7 \mathrm{~N}
\end{aligned}
$$

So the force that occurs on link 3 $\left(F_{3}\right)$ is $14.7 \mathrm{~N}$, the direction of the force is parallel to the $y$ axis.

Because the axis of motion on link3 is at the end of the rod, the moment of inertia that occurs at link 3 with the additional object load is expressed in:

$$
\begin{aligned}
& I=\frac{1}{3} \mathrm{~m} \cdot \mathrm{r}^{2} \\
& =\frac{1}{3} 1,5 \mathrm{~kg} \cdot 0,15 \mathrm{~m}^{2} \\
& =0,01125 \mathrm{~kg} \cdot \mathrm{m}^{2}
\end{aligned}
$$

\section{b. Calculating the force on the link}

$>$ To calculate the force on joint 2 is as follows:

$$
\boldsymbol{F}=\sum \boldsymbol{m} \cdot \boldsymbol{a}
$$

$$
\begin{aligned}
F_{2}= & 0,2 \mathrm{~kg} \cdot 9,8 \mathrm{~m} / \mathrm{s}^{2}+1,5 \mathrm{~kg} \cdot 9,8 \mathrm{~m} / \mathrm{s}^{2} \\
& =1,96 \mathrm{~N}+14,7 \mathrm{~N} \\
& =16,66 \mathrm{~N}
\end{aligned}
$$

So the force that occurs on link 2 is $15.68 \mathrm{~N}$, the direction of the force is parallel to the $y$ axis.

Because on link 2 the rotating axis is not located at the end of the rod as in Figure 4.3, the equation for the moment of inertia that occurs in link 2 uses the parallel axis theorem

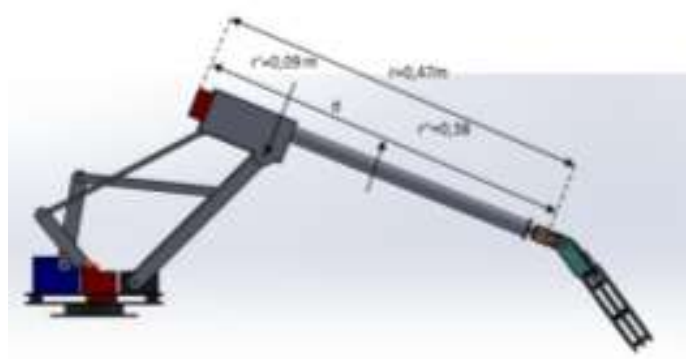


Motion link shaft 2

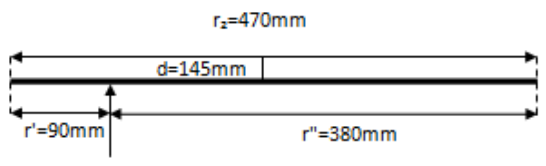

Link radius 2

$I=I s+I_{3}$

Where :

$I s=I p m+M d^{2}$

And Ipm is stated in :

$\operatorname{Ig} m=\frac{1}{12} m r^{2}$

$d=\frac{r}{2}-r^{\prime}$

Maka :

$I_{2}=I p m+m d^{2}+I_{3}$

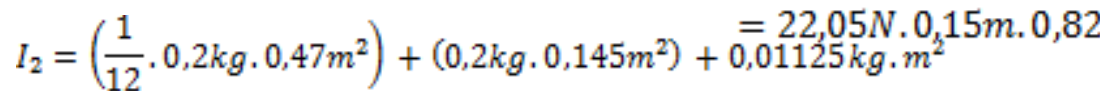

$=0,003681 \mathrm{~kg} \cdot \mathrm{m}^{2}+0,004205 \mathrm{~kg} \cdot \mathrm{m}^{2}+0,01125 \mathrm{~kg} \cdot \mathrm{m}^{2}$

$=0,019136 \mathrm{~kg} \cdot \mathrm{m}^{2}$

So the moment of inertia on link 1 is $0.038719 \mathrm{~kg} \cdot \mathrm{m}^{2}$.

\section{c. Calculate the torque that occurs}

\section{at joints 1, 2 and 3}

To calculate the torque required for the servo motor of each joint, some supporting data is needed. Among them are the accepted force $(F)$, the link length ( $r$ ). For safety, the authors add $50 \%$ to the force of each joint.

The joint and link arrangement of the 3 DOF robot arms designed in this module in the form of a free body diagram is shown in the following figure:

$$
=2,7 \mathrm{Nm}
$$

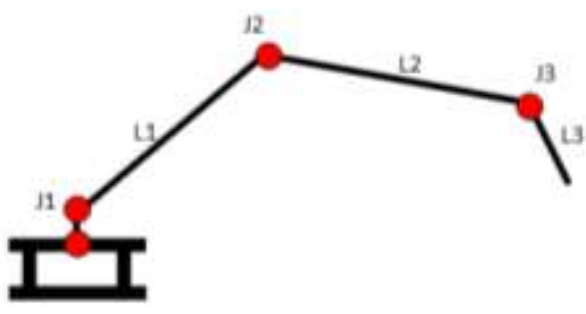

Free 2 dimensional body diagram

1) Calculates the torque at joint 3.

To find out the torque that works on joint 3 is:

$\mathrm{F}_{3}=14,7 \mathrm{~N}+(14,7 \mathrm{~N} \cdot 50 \%)=22,05 \mathrm{~N}$

$r_{3}=150 \mathrm{~mm}=0,15 \mathrm{~m}$

$\theta=125^{\circ}$

settlement (2. 23):

$T=F \cdot r \cdot \sin \theta$

$T=22,05 N \cdot 0,15 m \cdot \sin 125^{\circ}$

Based on the above calculations, the minimum recommended torque in selecting a servo motor for joint 3 is $2.7 \mathrm{Nm}$.

From the data above, the angular acceleration at joint 3 is expressed as:

$T=I . \alpha$

If know :

$T=2,7 \mathrm{Nm}$

$\mathrm{I}_{3}=0,01125 \mathrm{~kg} \cdot \mathrm{m}^{2}$.

Then :

$\alpha=\frac{T}{I}$ 


$$
\begin{aligned}
& =\frac{2,7 \mathrm{Nm}}{0,01125 \mathrm{~kg} \cdot \mathrm{m}^{2}} \\
& =240 \mathrm{rad} / \mathrm{s}^{2}
\end{aligned}
$$

So the angular acceleration that occurs at joint 3 is $240 \mathrm{rad} / \mathrm{s}^{2}$.

2) Menghitung torsi pada joint 2. joint 2 is:

To find out the torque acting on

$F_{2}=16,66 \mathrm{~N}+(16,66 \mathrm{~N} \cdot 50 \%)=24,99 \mathrm{~N}$

$r_{2}=380 \mathrm{~mm}=0,38 \mathrm{~m}$

$\theta=89^{\circ}$

completion :

$T=F \cdot r \cdot \sin \theta$

$T=24,99 N \cdot 0,38 m \cdot \sin 89^{\circ}$

$=24,99 \mathrm{~N} \cdot 0,38 \mathrm{~m} \cdot 0,99$

$=9,4 \mathrm{Nm}$

Based on the above calculations, the minimum recommended torque in selecting a servo motor for joint 2 is $9.4 \mathrm{Nm}$.

From the data above, the angular acceleration at joint 3 is stated:

$T_{2}=9,4 N m$

$I_{2}=0,019136 \mathrm{~kg} \cdot \mathrm{m}^{2}$

$\alpha=\frac{T_{2}}{I_{2}}$

$=\frac{9,4 \mathrm{Nm}}{0,019136 \mathrm{~kg} \cdot \mathrm{m}^{2}}$

$=491 \mathrm{rad} / \mathrm{s}^{2}$

So the angular acceleration that occurs at joint 2 is $491 \mathrm{rad} / \mathrm{s}^{2}$.
3) Calculating the torque at joint 1. joint 1 is:

To find out the torque acting on

$F_{1}=16,758 \mathrm{~N}+(16,758 \mathrm{~N} \cdot 50 \%)=25,137 \mathrm{~N}$

$r_{1}=250 \mathrm{~mm}=0,25 \mathrm{~m}$

$\theta=120^{\circ}$

Completion :

$T=F \cdot r \cdot \sin \theta$

$T=25,137 N \cdot 0,25 m \cdot \sin 120^{\circ}$

$=25,137 N \cdot 0,25 \cdot 0,87$

$=5,5 \mathrm{Nm}$

Based on the above calculations, the minimum recommended torque in selecting a servo motor for joint 1 is $5.5 \mathrm{Nm}$.

From the data above, the angular acceleration at joint 1 is stated:

$T_{1}=5,5 \mathrm{Nm}$

$I_{1}=0,038719 \mathrm{~kg} \cdot \mathrm{m}^{2}$

$\alpha=\frac{T_{1}}{I_{1}}$

$=\frac{5,5 \mathrm{Nm}}{0,038719 \mathrm{~kg} \cdot \mathrm{m}^{2}}$

$=142 \mathrm{rad} / \mathrm{s}^{2}$

So the angular acceleration that occurs at joint 1 is $142 \mathrm{rad} / \mathrm{s}^{2}$.

\subsection{Maximum load testing}

After the design and assembly process starting from the foundation to the robot arm frame is complete, the next step is the process of testing the robotic arm system in stages. 
The first test starts from the movement of the last link, then goes to the link closest to the foundation. The load used for testing on links 3 and 2 adjusts the mass of the object on the object being lifted, which is \pm 1.23 $\mathrm{kg}$. While in link 1 testing, load trials are carried out gradually. Test result data can be seen in the table below:

Table 4. 1 Load test results

\begin{tabular}{|c|l|c|c|}
\hline No & $\begin{array}{c}\text { Pengujian } \\
\text { pada }\end{array}$ & $\begin{array}{c}\text { Beban } \\
\text { tambahan }\end{array}$ & Hasil \\
\hline 1 & Link 3 & - & Work well \\
\hline 2 & Link 3 & $\pm 1,2 \mathrm{~kg}$ & Work well \\
\hline 3 & Link 2 & - & Work well \\
\hline 4 & Link 2 & - & Work well \\
\hline 5 & Wrist roll & $\pm 1,2 \mathrm{~kg}$ & Work well \\
\hline 6 & Wrist roll & - & Work well \\
\hline 7 & Link 1 & $0,5 \mathrm{~kg}$ & Work well \\
\hline 8 & Link 1 & $1 \mathrm{~kg}$ & Work well \\
\hline 9 & Link 1 & $1,2 \mathrm{~kg}$ & Work well \\
\hline 10 & Link 1 & $1,5 \mathrm{~kg}$ & Work hard \\
\hline 11 & Link 1 & $2 \mathrm{~kg}$ & Not able to \\
\hline 12 & Link 1 & - & Work \\
\hline 13 & Base rotation & $1,2 \mathrm{~kg}$ & Work well \\
\hline 14 & Base rotation & &
\end{tabular}

\subsection{Planning the joint 2 brace and wrist roll shaft.}

In this section, the author will calculate several points that are considered to be affected by the highest load, so that they have the potential for yield strength in the material to be more than other areas. Some points that are considered to be affected by high loads can be seen in the figure:

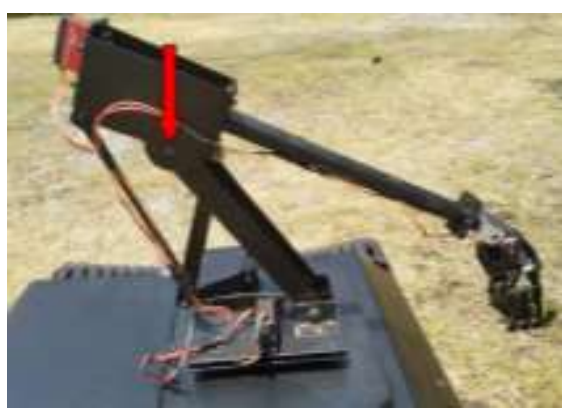

Joint brace 2 a. If seen in the picture above, it can be concluded that the Pen at joint 2 gets the greatest force. The stress acting on the Pen is the shear stress $($ Ssyp $=\mathrm{T})$. From the above calculations, it is known that the force acting on joint 2 is $16.66 \mathrm{kgf} . \mathrm{F}=16,66$ $\mathrm{kgf}$

$\mathrm{SF}=2$

Syp Pen $=20 \mathrm{kgf} / \mathrm{mm}^{2}$

To find the allowable Pen diameter:

$\tau \leq \| \tau \mid$

$\frac{F}{A} \leq|\tau|$

$\frac{16,66 \mathrm{kgf}}{\frac{1}{4} \pi \cdot d^{2}} \leq \frac{0,58.20 \mathrm{kgf} / \mathrm{mm}^{2}}{2}$

$\frac{1}{4} \cdot 3,14 \cdot d^{2} \cdot 0,58 \cdot 20 \frac{\mathrm{kgf}}{\mathrm{mm}^{2}} \geq 16,66 \mathrm{kgf} \cdot 2$

$9,106 \frac{\mathrm{kgf}}{\mathrm{mm}^{2}} \cdot d^{2} \geq 33,32 \mathrm{kgf}$

$d^{2}=\frac{33,32 \mathrm{kgf}}{9,106 \mathrm{kgf} / \mathrm{mm}^{2}}$

$d^{2}=3,7 m^{2}$

$d=\sqrt{3,7 \mathrm{~mm}^{2}}$

$d=1,9 \mathrm{~mm}$

From the above calculations it can be concluded that the minimum diameter of the pen for a safe joint 2 is $1.9 \mathrm{~mm}$.

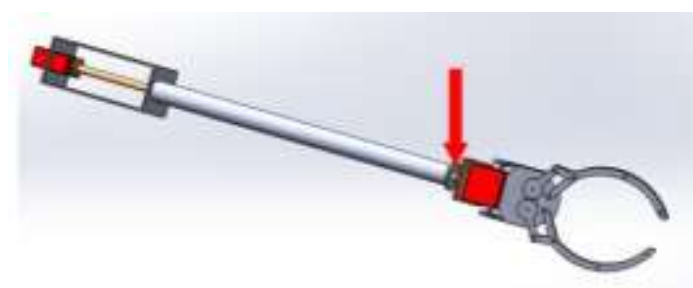

Wrist rotating shaft 
b. In the picture above, it is shown that there is a torsional moment (Mt). The torsional moment occurs when there is a rotation of $90^{\circ}$ in the end effector. To find out the allowable shaft diameter, it is necessary to find how much bending moment $(\mathrm{Mb})$ is borne on the shaft if the power and rotation are taken from the technical data of the JX PDI $6221 \mathrm{MG} 20 \mathrm{Kg}$ servo motor used to rotate the shaft.

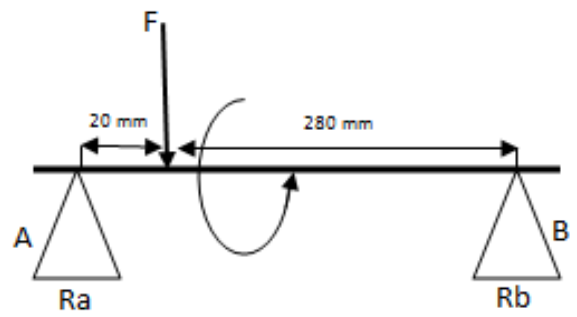

Free body shaft diagram

$$
\begin{aligned}
& \mathrm{F}=14,7 \mathrm{~N} \\
& \mathrm{~N}=0,0064 \mathrm{Hp} \\
& \mathrm{n}=62,4 \mathrm{Rpm} \\
& \text { Syp }=50 \mathrm{kgf} / \mathrm{mm}^{2} \\
& \mathrm{~L}=300 \mathrm{~mm} \\
& \mathrm{~L} 1=20 \mathrm{~mm} \\
& \mathrm{~L} 2=280 \mathrm{~mm} \\
& \mathrm{SF}=2 \\
& \text { Shaft Diameter }=\text { ? } \\
& \Sigma M A=0 \\
& \text { F. } \mathrm{L} 1-\mathrm{Rb} . \mathrm{L}=0 \\
& 14,7 \mathrm{~N} .20 \mathrm{~mm}-\mathrm{Rb} .300 \mathrm{~mm}=0 \\
& R b=\frac{294 \mathrm{~N} \cdot \mathrm{mm}}{300 \mathrm{~mm}}=0,98 \mathrm{~N} \\
& F=R a+R b \\
& 14,7 N=R a+0,98 N \\
& R a=14,7 N-0,98 N \\
& =13,7 \mathrm{~N}=1,4 \mathrm{kgf}
\end{aligned}
$$

$$
\begin{aligned}
& M T=716200 \cdot \frac{N}{n} \\
& =716200 \cdot \frac{0,00064 \mathrm{Hp}}{62,4 \mathrm{Rpm}} \\
& =73,456 \mathrm{kgf} . \mathrm{mm} \\
& M b=F . L 1 \\
& =R a .2 \\
& =1,4 \mathrm{kgf} .20 \mathrm{~mm} \\
& =28 \mathrm{kgf} \cdot \mathrm{mm} \\
& \tau \max = \\
& \frac{5,1}{d^{3}} \sqrt{M b^{2}+M T^{2}} \\
& \leq \quad \underline{0} \\
& = \\
& \frac{5,1}{d^{3}} \sqrt{(28 \mathrm{kgf} \cdot \mathrm{mm})^{2}+(73,456 \mathrm{kgf} \cdot \mathrm{mm})^{2}} \\
& \leq \quad \frac{0,58.50 \mathrm{kgj}}{2} \\
& \begin{array}{c}
= \\
\frac{5_{1} 1}{d^{3}} \sqrt{\left(784 \mathrm{kgf}^{2} \cdot \mathrm{mm}^{2}\right)+\left(5395,784 \mathrm{kgf} f^{2} \cdot \mathrm{mm}^{2}\right)}
\end{array} \\
& \leq \quad \underline{29 \mathrm{~kg}} \\
& = \\
& \frac{5,1}{d^{3}} \sqrt{6179,784 \mathrm{kgf}^{2} \cdot \mathrm{mm}^{2}} \\
& \leq 14,5 \mathrm{kgf} / \\
& =\frac{5,1.78,6 \mathrm{kgf} \cdot \mathrm{mm}}{d^{3}} \leq 14,6 \mathrm{kgf} / \mathrm{mm}^{2} \\
& =\frac{400,84 \mathrm{kgf} \cdot \mathrm{mm}}{14,5 \mathrm{kgf} / \mathrm{mm}^{2}} \leq d^{3} \\
& =27,65 \mathrm{~mm}^{3} \leq d^{3} \\
& d=\sqrt[s]{27,64 m m^{3}} \\
& =5,86 \mathrm{~mm}
\end{aligned}
$$

\subsection{Designing the gripper}

The gripper is one of the main components in designing a robot arm. Apart 
from being an end effector, the gripper is also an actuator that executes the object to be moved. The griper design is as shown in the image below.

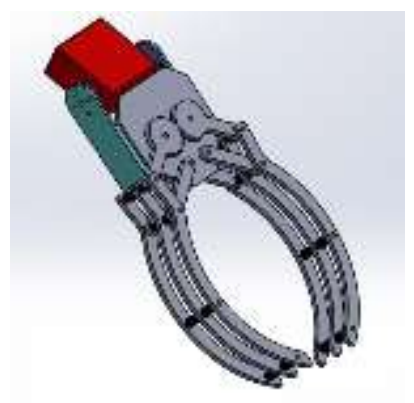

Planned gripper model

\section{motor}

a. Determine the gripper drive servo

As an actuator that carries out execution on objects, apart from being proportional to the mechanical system, the servo motor selection must be in accordance with the required specifications. The force acting on the tip jaws of the gripper is calculated to determine the torque required by the motor. If the mechanical construction of the gripper is considered good, then the next step is to determine the servo motor specifications in accordance with the object to be lifted.

So if the mass of the object is converted into a force, it is as follows:

$F=m \cdot g$

$F=1,23 \mathrm{~kg} \cdot 9,8 \mathrm{~m} / \mathrm{s}^{2}$

$=12,054 \mathrm{~N}$

For the safety factor, $50 \%$ of the force of the object being lifted will be added.

$$
\begin{aligned}
& F=12,054 \mathrm{~N}+(12,054 \mathrm{~N} \cdot 50 \%) \\
& =12,054 \mathrm{~N}+6,027 \mathrm{~N} \\
& =18,081 \mathrm{~N}
\end{aligned}
$$

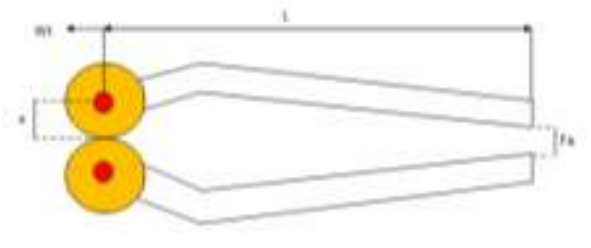

Gripper chuck test

The mechanism that acts on the gripper can be seen in the picture

Fa : $18,081 \mathrm{~N}$

$\mathrm{L}=100 \mathrm{~mm}$

$X=20 \mathrm{~mm}$

Completion :

$F a \cdot L=W t . x$

$18.081 \mathrm{~N} .100 \mathrm{~mm}=W t .20 \mathrm{~mm}$

$W t=\frac{18,081 \mathrm{~N} .100 \mathrm{~mm}}{20 \mathrm{~mm}}$

$=\frac{1808,1 \mathrm{~N} \cdot \mathrm{mm}}{20 \mathrm{~mm}}$

$=90,405 \mathrm{~N}$

Table 4. 2 Comparison of contact voltage

\begin{tabular}{|c|c|c|c|c|}
\hline $\mathrm{Na}$ & $\begin{array}{l}\text { Torsi } \\
\text { (Kmi }\end{array}$ & $\begin{array}{l}\text { Aeban targesiel } \\
\text { dtrarnisian W: } \\
\text { [W] }\end{array}$ & $\begin{array}{l}\text { Tegangan } \\
\text { bentak oc garuai } \\
\text { AGMA (MPa) }\end{array}$ & $\begin{array}{c}\text { Tegangon } \\
\text { tama Geracua } \\
\text { ANSB (VPa) }\end{array}$ \\
\hline 1 & 80 & 256 & 835 & 956 \\
\hline 2 & 150 & 471 & 1140 & 1198 \\
\hline 3 & 200 & 652 & 1350 & 1396 \\
\hline 4 & 280 & 8077 & 1510 & 1578 \\
\hline 5 & 325 & 9.42 & 1643 & 1718 \\
\hline 6 & 340 & 10.50 & 1754 & 1797 \\
\hline 7 & 375 & 1154 & 1850 & 1988 \\
\hline 8 & 45 & 1256 & 1932 & 1978 \\
\hline 9 & 430 & 1338 & 2000 & 2099 \\
\hline 10 & 450 & 1412 & 2067 & 2179 \\
\hline
\end{tabular}
prices according to AGMA and ANSYS

According to the comparison of the price of the contact voltage according to AGMA and 
ANSYS, it is possible to find the motor torque needed to move the gripper clamp. From the calculation of tangential load $(\mathrm{Wt})$ above, it is found that $\mathrm{Wt}=90.405 \mathrm{~N}$. Based on the comparison table above, the torque is stated as follows:

$\mathrm{T}_{1}=80 \mathrm{Nm}$

$\mathrm{Wt}_{1}=2,56 \mathrm{kN}=2560 \mathrm{~N}$

$\mathrm{Wt}_{2}=90,405 \mathrm{~N}$

Then :

$\frac{T_{1}}{T_{2}}=\frac{W t_{1}}{W t_{2}}$

$\frac{80 \mathrm{Nm}}{T_{2}}=\frac{2560 \mathrm{~N}}{90,405 \mathrm{~N}}$

$T^{2}=\frac{80 \mathrm{Nm} \cdot 90,405 \mathrm{~N}}{2560 \mathrm{~N}}$

$=\frac{7232,4 N^{2} m}{2560 N}$

$=2,8 \mathrm{Nm}$

From the above calculations, it can be used as a reference for determining servo motor specifications. It can be concluded that the torque of the servo motor used must be more than $2.8 \mathrm{Nm}$ for the gripper to work safely.

\section{a. Gripper testing}

After completing the gripper assembly with the robot arm and the electrical system, the next step is to test the gripper function. Testing is stiffened to determine the function and ability of the gripper. Gripper motion control using a remote control. At this testing stage the steps taken are:

Tabel 4. 3 Gripper testing

\begin{tabular}{|c|c|c|c|}
\hline No & TESTING & RESULT & INFORMATION \\
\hline 1 & $\begin{array}{l}\text { Motion testing } \\
\text { gripper to open }\end{array}$ & Work well & \\
\hline
\end{tabular}

\begin{tabular}{|c|c|c|c|}
\hline & and close & & \\
\hline 2 & $\begin{array}{l}\text { Testing the } \\
\text { maximum angle } \\
\text { of the gripper } \\
\text { when opening }\end{array}$ & $\begin{array}{c}\text { Max angle } \\
120^{\circ}\end{array}$ & \\
\hline 3 & $\begin{array}{l}\text { Do the gripper } \\
\text { move gently }\end{array}$ & $\begin{array}{l}\text { Able to } \\
\text { move } \\
\text { gently }\end{array}$ & $\begin{array}{l}\text { Using the } \\
\text { potential } \\
\text { channel }\end{array}$ \\
\hline 4 & $\begin{array}{l}\text { Testing of } \\
\text { clamping objects } \\
\text { with different } \\
\text { shapes }\end{array}$ & $\begin{array}{l}\text { Able to } \\
\text { work }\end{array}$ & $\begin{array}{c}\text { Shape of object } \\
\text { (box,tube) }\end{array}$ \\
\hline 5 & $\begin{array}{l}\text { Testing of } \\
\text { carrying } \\
\text { detonator } \\
\text { simulator objects } \\
\text { by maneuvering } \\
\text { the base tank }\end{array}$ & $\begin{array}{c}\text { Able to } \\
\text { maintain } \\
\text { grip power }\end{array}$ & $\begin{array}{l}\text { The base Tank } \\
\text { runs for } \pm 50 \mathrm{~m}\end{array}$ \\
\hline 6 & $\begin{array}{l}\text { The test puts the } \\
\text { detonator } \\
\text { simulator on top } \\
\text { of the grenade } \\
\text { simulator }\end{array}$ & $\begin{array}{l}\text { Able to } \\
\text { work }\end{array}$ & \\
\hline
\end{tabular}

\subsection{Results and Diccussion}

From the planning stage to the testing phase, the results of the robot arm performance are as follows:

a. The manufacture of mechanical system construction is the application of predefined planning. Starting from engineering drawings, mechanical calculations, to the materials and equipment used.

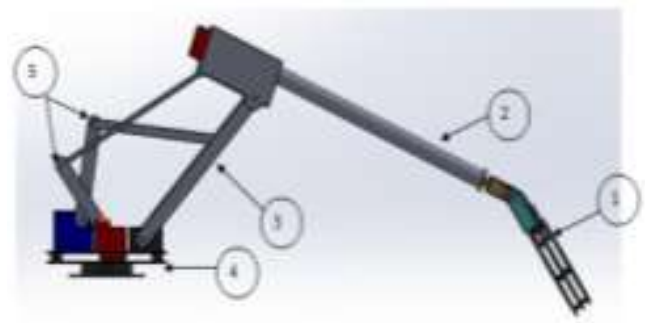

Mechanical designing :

\section{Caption :}

1. gripper Unit (link 3)

2. Arm up (link 2)

3. Arm down (link 1) 
4. arm foundation

5. link work lever $1 \& 2$

b. In designing the arm foundation, axial trush ball bearing is chosen because it is in accordance with the needs of axial movement at the base of the arm. The advantage of this axial trush ball bearing is that it is resistant to compressive forces. The application of this design is by connecting the servo motor holder with a self-designed coupling. Couplings are inserted into the axial trush ball bearing to hold the load above and locked using 4 bolts that are connected to the base tank. To withstand the axial motion of the arms, the foundation is fastened using 4 bolts with a diameter of $6 \mathrm{~mm}$.

c. In the initial design of the arm, the researcher placed the servo motor at each joint. However, there are constraints with a greater load force on the servo motor so that the authors consider that there is less energy efficiency. To reduce the torque load on the servo motor, the researchers added a lever that connects the servo motor with link 1 and link 2 . The result of the addition of this lever makes the torque released by the servo motor on link 1 and link 2 more efficient.

d. The placement of the servo motor used to rotate the end effector is to reduce the force load on the end of the arm.

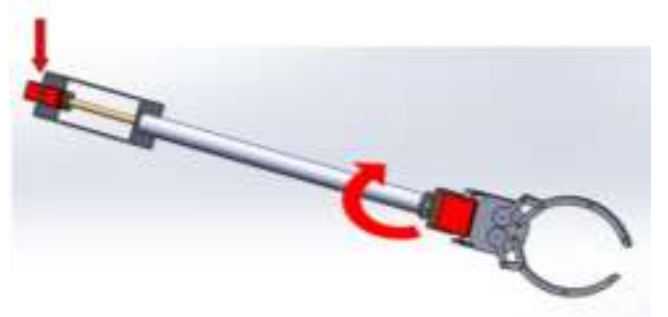

$90^{\circ}$ circular motion on the wrist

e. The component that plays an important role is the gripper, where the gripper functions as an actuator. That is, a component that executes the object to be carried. Therefore the gripper design must be strong and light, so that it can be operated optimally.

\section{CONCLUSIONS AND SUGGESTIONS}

\subsection{Conclusions}

In the design of the robot anipulator mechanism, it can be concluded as follows:

a. The robot arm design with a total length of horizontal arm stretch is $780 \mathrm{~mm}$ and $795 \mathrm{~mm}$ for vertical stretch.

b. The workspace of the robot arm starting from the foundation of the arm is made to rotate which can rotate as far as 120. On link 1 it moves $150^{\circ}$, link 2 is 150 $\circ$, link 3 is $90^{\circ}$, and link 5 is $180^{\circ}$.

c. The force acting on link 1 is $14.7 \mathrm{~N}$ in the direction of the force parallel to the $y$ axis, the torque is $5.5 \mathrm{Nm}$ and the angular acceleration is $142 \mathrm{rad} / \mathrm{s}^{2}$. From the results of the torque calculation above, it can be used as a guide for the selection of a servo motor on link 1 .

d. The force acting on link 2 is $16.758 \mathrm{~N}$, the direction of the force is parallel to the $y$ axis, the torque is $9.4 \mathrm{Nm}$ and the angular acceleration is 491rad / $\mathrm{s}^{2}$. From the results of the torque calculation above, it can be used as a guide for the selection of a servo motor on link 2.

e. The force acting on link 3 is $14.7 \mathrm{~N}$ in the direction of the force parallel to the $y$ axis, the torque is $2.7 \mathrm{Nm}$ and the angular acceleration is $240 \mathrm{rad} / \mathrm{s}^{2}$. From the results of the torque calculation above, it can be used as a guide for the selection of a servo motor on link 3 .

$f$ From the calculation of force and torque above, it can be concluded that the minimum torque in the selection of a servo motor for link 1 is $5.5 \mathrm{Nm}$, link 2 is $9.4 \mathrm{Nm}$ and link 3 is $2.7 \mathrm{Nm}$.

g. Taking into account the force of the object being lifted, the calculation results show that to move the gripper a torque of 2.8 Nm is required. These results can be used as a reference for selecting the appropriate servo motor. And from the results of the arm and gripper load testing by considering the results of the above calculations, the performance of the arm and gripper is as expected. 


\subsection{Suggestions}

Of all the design stages of the robot manipulator in the Unmaned grenade vehicle (UGV), then:

a. It is hoped that in the next research this tool can be developed in terms of construction to make it stronger and able to move more dynamically.

b. It is hoped that in further research the data, theory and application can be implemented in different equipment and functions.

\section{ACKNOWLEDGEMENT}

The authors greatly acknowledge the support from Naval Technology College, STTAL Surabaya Indonesia for providing the necessary resources to carry out this research work. The authors are also grateful to the anonymous reviewers and journal editorial board for their many insightful comments, which have significantly improved this article.

\section{REFERENCE}

Ardiyanto, R. (2019, januari 30). Momen Gaya (Torsi) Adalah - Pengertian, Rumus, Dan Contoh Soal. Dipetik mei 05, 2019, dari https://rumus.co.id/momen-gayatorsi-adalah/.

Ilham Vega Prayuda, Budi Hartono, Edi Sutoyo. (t.thn.). Perancangan struktur rangka lengan robot mekanik pemindah bahan tipe cartesian coordinate . 39-40.

Irawan, A. P. (2007). Diktat Kuliah Mekanika Teknik (Statika Struktur). 1-34.

Muhammad Fathul Faris, Aris Triwiyatno, Iwan Setiawan. (2012). Perancangan arm manipulator 4 DOF dengan menggunakan pengendalian cartesian space-trajectory planning.

Muhammad hidayat; muhammad agus syahroni; syahril ardi. (2016). Perancangan dan pembuatan gripper sebagai komponen. Simposium Nasional RAPI XV - FT UMS , 99.

R.S.Khurmi, J.K Ghupta. (1982). A Text Book Of Machine Design. newdelhi: Eurasia Publishing House (Pvt).

Roni permana saputra, E. (2012). trajectory scenario control for the remotely. control and network system , 851866.

Siswaja, h. d. (2008). prinsip kerja dan klasifikasi robot. media informatika, 151-152.

Sularso. (1997). Dasar perencanaan dan pemilihan Elemen Mesin. kiyokatsu suga: pradnya paramita.

Suratno, anton suseno, slamet sigit widodo. (2016). rancang bangun stick manipulator lengan berbasis mikrokontroler dengan sistem elektromekanik.

Widodo Budiharto, Ari Santoso, Djoko Purwanto, Achmad Jazidie. (2011). Multiple Moving Obstacles Avoidance of Service Robot. TELKOMNIKA . 